\title{
Quarterly Regional GDP Flash Estimates by Means of Benchmarking and Chain Linking
}

\author{
Ángel Cuevas ${ }^{1}$, Enrique M. Quilis ${ }^{2}$, and Antoni Espasa ${ }^{3}$
}

In this article we propose a methodology for estimating the GDP of a country's different regions, providing quarterly profiles for the annual official observed data. Thus the article offers a new instrument for short-term monitoring that allows the analysts to quantify the degree of synchronicity among regional business cycles. Technically, we combine time-series models with benchmarking methods to process short-term quarterly indicators and to estimate quarterly regional GDPs ensuring their temporal and transversal consistency with the National Accounts data. The methodology addresses the issue of nonadditivity, explicitly taking into account the transversal constraints imposed by the chain-linked volume indexes used by the National Accounts, and provides an efficient combination of structural as well as short-term information. The methodology is illustrated by an application to the Spanish economy, providing real-time quarterly GDP estimates, that is, with a minimum compilation delay with respect to the national quarterly GDP. The estimated quarterly data are used to assess the existence of cycles shared among the Spanish regions.

Key words: Benchmarking; chain linking; national accounts; regional accounts; GDP flash estimates.

\section{Introduction}

Business cycle analysis and the short-term monitoring of a national economy can be substantially improved if an explicit regional dimension is taken into consideration. In this way, the diffusion of the aggregate (or national) cycle can be analyzed in detail: identifying leading/coincident/lagged regions, detecting common and specific shocks and so on. The relevance of this added geographical dimension is especially important both for large or medium-sized countries as well as for countries with decentralized systems that allow specific economic policies to be applied. Of course, the quarterly regional estimates that we present below are also very useful for regional governments.

The Regional Accounts (RA) are annual data and in this context we here propose a methodology for estimating quarterly Gross Domestic Product (GDP) time series at the regional level, providing a new instrument for short-term monitoring that allows us to gauge the degree of synchronicity and the identification of shared and idiosyncratic shocks to different regions.

\footnotetext{
1 Macroeconomic Research Department, Independent Authority for Fiscal Responsibility, José Abascal n 2 , 2- planta 28003, Madrid, Spain. Email: angel.cuevas@airef.es

2 Macroeconomic Research Department, Independent Authority for Fiscal Responsibility, José Abascal n ${ }^{\circ} 2$, $2^{2}$ planta 28003, Madrid, Spain. Email: enrique.quilis@airef.es

3 Department of Statistics and Instituto Flores de Lemus, Universidad, Carlos III de Madrid, Calle Madrid 126, 28903 Madrid, Spain. Email: antoni.espasa@uc3m.es
} 
Our methodology ensures the consistency of these quarterly regional GDPs with the national quarterly GDP, taking into account the chain-linking procedures that underlie its compilation. Note that the same principles of volume estimation using chainlinked indices have been used in our analysis and we have applied the same procedures of seasonal and calendar adjustment used by the Quarterly National Accounts (QNA).

Structural consistency is also ensured, since the quarterly regional GDPs are consistent with their annual RA counterparts. The fact that both QNA and RA share the same National Accounts (NA) framework provides the base for the consistency obtained in our analysis. In this way, we can use the quarterly regional estimates to derive structural measures at the regional level.

The modeling approach is highly reliant on a set of regional high-frequency indicators. These indicators provide the ultimate basis used by the model to generate GDP according to time-series techniques ranging from univariate ARIMA models to multivariate dynamic-factor models. The set of indicators and models are homogeneous across regions, ensuring the comparability of the results.

The methodology has three main stages:

1. Processing of the high-frequency indicators available at the regional level and estimation, for each region, of a synthetic index that combines the available shortterm information.

2. Temporal disaggregation and interpolation of annual regional GDP using the indicators processed in Step 1.

3. Balancing of these initial quarterly estimates in order to ensure transversal consistency with national quarterly GDP, at the same time preserving the temporal consistency achieved in the previous stage.

It is worth emphasizing that, from an operational perspective, early estimates of quarterly regional GDPs may be available with a minimum delay with respect to the national quarterly GDP release, the so-called "GDP flash estimate". Thus the national figure may have timely regional counterparties, enhancing the informational content of analysis carried out at the aggregate level.

The main contributions of our article are:

- A methodology for obtaining quarterly estimates of GDP for all the regions in a country, derived in a consistent way with the official available data provided by the NA, both RA and QNA.

- Early (or flash) estimates of quarterly GDP at the regional level that may be released at the same time as the national GDP.

- Transversal consistency is compliant with the chain-linking methodology, circumventing its nonadditive features in the balancing step.

The article is organized as follows. The second section outlines the modeling approach, going into detail on its main steps. A complete and in-depth application of the methodology using Spanish data appears in section three. Finally, in the fourth section, we present our conclusions and future lines of research. 


\section{Modeling Approach}

In this section we present the main steps of the proposed methodology. The modeling approach consists of three basic steps: (i) seasonal adjustment of regional short-term raw indicators and construction of synthetic indicators for each region by means of factor analysis, (ii) initial quarterly estimates of regional GDP provided by benchmarking and (iii) enforcement of the transversal constraint that links the regional quarterly GDPs with their national counterpart.

This aggregation constraint must be consistent with the chain-linking procedure used to compile quarterly GDP at the national level, dealing with the nonadditivity issue in an appropriate way. We now turn to examine the three stages in more detail; however, to simplify the exposition, we first present the required information set.

\subsection{Information Set}

The model requires as input three elements that vary according to their sampling frequency (annual or quarterly), their spatial coverage (regional or national) and their method of compilation (NA or short-term indicators).

The variables of the system are: regional GDPs $(y)$, national GDP $(z)$, and regional short-term indicators in their original or raw form $(x r)$. Upper-case letters refer to annual variables, while lower-case letters refer to quarterly variables. Let $T=1, \ldots, N$ be the annual (low-frequency) index, $t=1, \ldots, 4$ the quarterly index within a natural year and $j=1, \ldots, M$ the regional (cross-section) index.

Hence, $Y=\left\{Y_{T, j}: T=1, \ldots, N ; j=1, \ldots, M\right\}$ is a $N x M$ matrix comprising the annual regional GDPs that play the role of temporal benchmarks of the system. Aggregation of the regional GDPs generates the GDP at the national level. Note that, aggregation is performed according to the chain-linking methodology.

Variable $z$ is a $n x l$ vector comprising the observed quarterly GDP provided by the QNA, being $n$ the number of quarterly observations satisfying $n \geq 4 N$. This figure is available more timely than the regional data and shares with them the corresponding annual GDP volume index:

$$
Z_{T}=\frac{1}{4} \sum_{t \in T} z_{t, T}
$$

For example, taking 2011 as a reference, the QNA released its first estimate of 2010:Q4 on February, 11 while the RA released its first estimate of 2010 on March, 24. Both estimates share the annual figure for 2010 implicitly provided by the QNA by means of temporal aggregation of the four quarters of 2010.

Finally, $x r$ is a $n x M$ matrix comprising the observed raw quarterly indicators that operate as high-frequency proxies for the regional aggregates $Y$. As will be explained later, we work with the seasonally and calendar-adjusted indicators $(x)$ instead of the raw indicators $(x r)$.

Only the indicators $x$ are observed at the three dimensions of the system: $T$ (annual index), $t$ (quarterly index) and $j$ (regional index). Therefore, they provide the interpolation basis for $Y$ (across the quarterly dimension $t$ ) and $z$ (across the regional dimension $j$ ). 
Table 1. Information set of the model: Quarterly GDP tracker (x), Annual Regional GDP (Y), quarterly National GDD (Z) and Quarterly Regional GDP (y), which is the variable to be estimated.

\begin{tabular}{|c|c|c|c|c|c|c|c|c|}
\hline \multirow[b]{2}{*}{ Year } & \multirow[b]{2}{*}{ Quarter } & \multicolumn{3}{|c|}{ Region 1} & \multicolumn{3}{|c|}{ Region 2} & \multirow{2}{*}{$\begin{array}{c}\text { Nation } \\
\mathrm{Z}\end{array}$} \\
\hline & & $\mathrm{x}_{1}$ & $\mathrm{y}_{1}$ & $\mathrm{Y}_{1}$ & $\mathrm{x}_{2}$ & $\mathrm{y}_{2}$ & $\mathrm{Y}_{2}$ & \\
\hline \multirow{4}{*}{1} & 1 & $\mathrm{x}_{1,1,1}$ & $\mathrm{y}_{1,1,1}$ & \multirow{4}{*}{$Y_{1,1}$} & $\mathrm{x}_{2,1,1}$ & $\mathrm{y}_{2,1,1}$ & \multirow{4}{*}{$Y_{2,1}$} & $\mathbf{z}_{2, \mathbf{1}, \mathbf{1}}$ \\
\hline & 2 & $\mathrm{x}_{1,2,1}$ & $\mathrm{y}_{1,2,1}$ & & $x_{2,2,1}$ & $\mathrm{y}_{2,2,1}$ & & $\mathbf{z}_{2,2,1}$ \\
\hline & 3 & $\mathrm{X}_{1,3,1}$ & $\mathrm{y}_{1,3,1}$ & & $\mathrm{x}_{2,3,1}$ & $\mathrm{y}_{2,3,1}$ & & $z_{2,3,1}$ \\
\hline & 4 & $\mathrm{x}_{1,4,1}$ & $\mathrm{y}_{1,4,1}$ & & $\mathrm{x}_{2.4,1}$ & $\mathrm{y}_{2,4,1}$ & & $\mathbf{z}_{2,4,1}$ \\
\hline \multirow[t]{4}{*}{2} & 1 & $\mathrm{X}_{1,1,2}$ & $\mathrm{y}_{1,1,2}$ & & $\mathrm{x}_{2,1,2}$ & $\mathrm{y}_{2,1,2}$ & & $\mathbf{Z}_{2,1,2}$ \\
\hline & 2 & $\mathrm{X}_{1,2,2}$ & $\mathrm{y}_{1,2,2}$ & & $x_{2,2,2}$ & $\mathrm{y}_{2,2,2}$ & & $\mathrm{z}_{2,2,2}$ \\
\hline & 3 & & & & & & & \\
\hline & 4 & & & & & & & \\
\hline
\end{tabular}

Note: bold variables are temporal constraints $(Y)$ or transversal constraints $(z)$.

In other words, our objective is to estimate $y$ using $x$ as interpolators and consistently with both $Y$ and $z$.

Table 1 sets out the relationship among the inputs $(Y, z$ and $x)$ and the output $(y)$ of the system for a simplified case with two regions $(M=2)$ and two years $(T=2)$. The first year is complete while the second year is incomplete (i.e., the last two quarters are not available for $x$ and $z$ and the annual figure for $Y$ is not available either).

In this simplified example, we want to estimate the first year's quarterly regional GDPs $y_{j, t, 1}$ consistently with their annual counterparts $Y_{j, 1}$ and satisfying the transversal constraint that links the regional GDPs with the national GDP $z_{t, l}$ each quarter. The annual constraints do not apply during the second year since $Y_{j, 2}$ are not available. Thus the only binding constraint is the transversal constraint.

\subsection{Processing Short-Term Indicators}

Typically, short-term regional economic indicators are compiled in raw form by the statistical agencies. However, the volume GDP used for short-term monitoring at the national level is calculated in two ways: using raw indicators or using seasonal and calendar-adjusted indicators. Since seasonal and calendar effects could be quite different between indicators and the macroeconomic aggregates, the second procedure for the calculation of the GDP seems more reliable. Usually these GDP figures are referred to as seasonal and calendar adjusted.

In order to ensure the homogeneity between both sources of information, regional raw indicators and seasonally adjusted quarterly national GDP, we apply an ARIMA modelbased correction that filters out the raw data from seasonal and calendar effects, if they are present. The procedure has been implemented using the TRAMO-SEATS program, see Gómez and Maravall (1996) and Caporello and Maravall (2004). Formally:

$$
x_{j, t, T}=V\left(B, F ; \psi_{j}\right) x r_{j, t, T}
$$

where $x r_{j, t, T}$ is the raw short-term indicator; $V()$ is the Wiener-Kolmogorov filter symmetrically defined on the backward and forward operators $B$ and $F$ and $\psi_{j}$ are the 
parameters of the filter derived consistently with those of the ARIMA model for $x r_{j, t, T}$, see Gómez and Maravall (1998a, 1998b) for a detailed exposition of the model-based approach used by TRAMO-SEATS.

If the indicators are available at the monthly frequency, seasonal adjustment is performed on the monthly series. The resulting series are temporally aggregated to the quarterly frequency.

We have used TRAMO-SEATS because it is the method used by the Spanish National Statistical Institute (NSI) to adjust GDP to seasonal effects. Of course, the choice of the seasonal adjustment procedure depends on the official method used by the NSI to produce the GDP figures. In countries where X12-ARIMA is the official procedure, this should be also the choice for seasonally adjusting the short-term indicators.

In practice, several short-term economic indicators are used to monitor and estimate regional GDPs. These indicators are individually processed according to (2) and then linearly combined, producing a composite indicator that will be used as the high-frequency proxy for regional GDPs. As will be explained in the third section, we use factor analysis to estimate a synthetic indicator for each region because it provides an objective and simple way to combine the available indicators.

\subsection{Initial Quarterly Regional GDP Estimation}

Preliminary estimates of quarterly GDP at the regional level are compiled using benchmarking techniques (see Di Fonzo 1987, 2002 and Proietti 2006 for an in-depth exposition). These techniques play an important role in the compilation practices of QNA around the world (see Eurostat 1998 and Bloem et al. 2001).

We have considered several benchmarking procedures for deriving the preliminary GDP estimates: Chow and Lin (1971), Fernández (1981), Santos-Silva and Cardoso (2001) and Proietti (2006). All of them hinge upon a dynamic linear model that links the (observable) high-frequency indicator with the (unobservable) regional GDP. (To keep the notation simple we have omitted the regional index $j$ ).

$$
y_{t}=\phi y_{t-1}+\beta_{0} x_{t}+\beta_{1} x_{t-1}+u_{t}
$$

The innovation $u$ follows an $\operatorname{AR}(1)$ process:

$$
u_{t}=\rho u_{t-1}+a_{t}
$$

Finally, the random shock that drives the innovation $u$ is the Gaussian white-noise process:

$$
a_{t} \sim \operatorname{iid} N\left(0, v_{a}\right)
$$

The model includes a temporal constraint that makes $y$ quantitatively consistent with its annual counterpart $Y$ :

$$
Y=C y
$$

$C$ is the temporal aggregation-extrapolation matrix defined as:

$$
C=\left(I_{N} \otimes c \mid O_{N, n-s N}\right)
$$

where $N$ is the number of low-frequency observations, $\otimes$ stands for the Kronecker product, 
Table 2. Benchmarking methods

\begin{tabular}{llll}
\hline & \multicolumn{3}{c}{ Parameter } \\
\cline { 2 - 4 } Method & $\phi$ & $\beta_{1}$ & $\rho$ \\
\hline Chow-Lin & 0 & 0 & $(0,1)$ \\
Fernández & 0 & 0 & 1 \\
Santos Silva-Cardos & $(0,1)$ & 0 & 0 \\
Proietti & $(0,1)$ & $\neq 0$ & 0 \\
\hline
\end{tabular}

$c$ is a row vector of size $s$ which defines the type of temporal aggregation and $s$ is the number of high-frequency data points for each low-frequency data point. If $c=[1,1, \ldots, 1]$ we would have the case of the temporal aggregation of a flow, if $c=[1 / s, 1 / s, \ldots, 1 / s]$ the case of the average of an index, and if $c=[0,0, \ldots, 1]$, an interpolation would be obtained. In our case, $s=4$.

Extrapolation arises when $n>s N$. In this case, the problem can be solved easily by simply extending the temporal aggregation matrix by considering new columns of zeroes which do not distort the temporal aggregation relationship and that do not pose any difficulty to the inclusion of the last $n-s N$ data points of the indicators in the process of estimating $y$.

The different benchmarking methods depend on the values of the parameters in (3) and (4) according to Table 2.

The methods of Chow-Lin and Fernández place the dynamics in the innovation, which may follow a stationary AR(1) process (Chow-Lin) or a nonstationary I(1), random-walk process (Fernández). Litterman (1983) proposes a methodology close to those of Chow-Lin and Fernández. However, the empirical and Monte Carlo evidence show that its performance is sometimes disappointing. This is due to the flatness of the implied likelihood profile and, therefore, the corresponding observational equivalence in a wide range of values for its dynamical parameter, see Proietti (2006). On the other hand, the methods of Santos Silva-Cardoso and Proietti place the dynamics in the variables $y$ and $x$, treating the innovation as a purely random shock. Gregoir (1994) and Salazar et al. (1994) also propose methods in which the dynamics of $y$ and $x$ play an explicit role.

The estimation of the parameters and the unobserved time series $y$ is performed by maximizing the implied log-likelihood profile of the low-frequency model. The lowfrequency model incorporates the temporal aggregation constraints [2.6] and [2.7]. This optimization is performed by means of a grid search on the stationary domain of $\phi$ or $\rho$ and pinning down the values of $\beta$ and $\sigma$ that maximize the log-likelihood function conditioned on the selected value for $\phi$ or $\rho$ (see Bournay and Laroque 1979 for an in-depth exposition). The computations have been carried out using the functions written in Matlab by Abad and Quilis (2005).

\subsection{Balancing in a Chain-Linking Setting}

The estimates derived in the previous step do not verify the transversal constraint that should relate them to the national quarterly GDP, satisfying the same type of relationship that links annual regional GDPs and annual national GDP. We solve the problem by 
applying a multivariate balancing procedure, in particular a multivariate extension of the Denton (1971) method. This extension can be expressed in matrix form (as in Di Fonzo 1990 and Di Fonzo and Marini 2003), as well as in state-space form (see Proietti 2011). In this article we have adopted the former approach, using the functions written in Matlab by Abad and Quilis (2005).

This balancing method depends on the formulation of additive constraints. However, volume indexes compiled according to the chain-linking methodology are nonadditive, see Bloem et al. (2001) and Abad et al. (2007). Fortunately, we can transform the chain-linked measures in order to write them in an additive form and then use the powerful machinery of balancing procedures to ensure transversal and temporal consistency. Finally, we can express the results in the initial chain-linked format by reversing the transformation.

The constraint that links regional and national quarterly volume GDP is:

$$
z_{t, T}=\left(\sum_{j} W_{j, T-1} \frac{y_{j, t, T}}{Y_{j, T-1}}\right) Z_{T-1}
$$

where $z_{t, T}$ is the national quarterly volume GDP, $W_{j, T-1}$ is the weight of region $j$ in year $T-1$ and $y_{j, t, T}$ is the quarterly volume GDP of the $j$ th region. Weights are computed using GDPs valued at current prices, see Abad et al. (2007) for a complete derivation. Finally, $Z_{T}$ and $Y_{j, T}$ are the annual counterparts $z_{t, T}$ of and $y_{j, t, T}$.

After some algebraic manipulations, we can express the constraint in additive form:

$$
\underbrace{\frac{z_{t, T}}{Z_{T-1}}}_{r_{t, T}}=\underbrace{\sum_{j} W_{j, T-1} \frac{y_{j, t, T}}{Y_{j, T-1}}}_{w r_{j, t, T}}=\sum_{j} w r_{j, t, T}
$$

In (9), the relationship between the national ratio $r_{t, T}$ and the weighted regional ratios $\mathrm{w} r_{j, t, T}$ is additive.

Plugging the initial estimates derived according to (3)-(7) into (9), we obtain the preliminary, unbalanced estimates:

$$
w r_{j, t, T}^{*}=W_{j, T-1} \frac{\hat{y}_{j, t, T}}{Y_{j, T-1}}
$$

The balanced and temporally consistent time series $\mathrm{w} r_{j, t, T}^{* *}$ are the output of the following constrained quadratic optimization program:

$$
\underset{w r^{*}}{\operatorname{MIN}}\left(w r^{* *}-w r^{*}\right)^{\prime} D^{\prime} D\left(w r^{* *}-w r^{*}\right) \quad \text { s.t. } \quad H w r^{* *}=R_{e}
$$

being:

$$
H=\left[\begin{array}{c}
1_{M} \otimes I_{n} \\
I_{M} \otimes C
\end{array}\right] \text { and } R_{e}=\left[\begin{array}{c}
z \\
W R
\end{array}\right]
$$

where $l_{M}$ is a column vector of ones and $W R$ is the annual counterpart of the weighted regional ratios written in matrix form.

In program (11), the objective function reflects the volatility of the discrepancies between the quarter-to-quarter growth rates of the balanced series and those of the 
unbalanced ones. After some mathematical manipulation, an explicit expression can be derived:

$$
w r^{* *}=w r^{*}+\left(D^{\prime} D\right)^{-1} H^{\prime}\left[H\left(D^{\prime} D\right)^{-1} H^{\prime}\right]^{-1}\left(R_{e}-H w r^{*}\right)
$$

The interpretation of Equation (12) is straightforward: the quarterly balanced series are the result of adding a correction factor to the unbalanced series. This correction factor derives from the distribution of the discrepancy between the preliminary unbalanced estimates and the constraint series $R_{e}$.

Once we have obtained the consistent weighted ratios, we can reverse the transformation (9) to derive the final estimates of the quarterly regional GDP in volume terms:

$$
y_{j, t, T}^{* *}=w r_{j, t, T}^{* *} \frac{Y_{j, T-1}}{W_{j, T-1}}
$$

In this way, the estimates of quarterly GDP derived in the previous equation are quantitatively consistent in their time dimension (taking as benchmark their annual regional counterparts) and in their cross-section dimension (generating the GDP provided by the QNA by regional aggregation). We should also emphasize that the consistency extends to the methodological dimension too, since the chain-linking procedures currently used by the NA have been properly taken into account. Finally, using time-series methods to project the basic short-term indicators, we can derive nowcasts (or flash estimates) of regional quarterly GDP in a timely manner.

As a summary, Figure 1 presents a picture of the complete procedure. The diagram emphasizes the binding constraints and the homogeneous processing of information at the regional level. Note that the box labeled "balancing" embeds the dechaining and

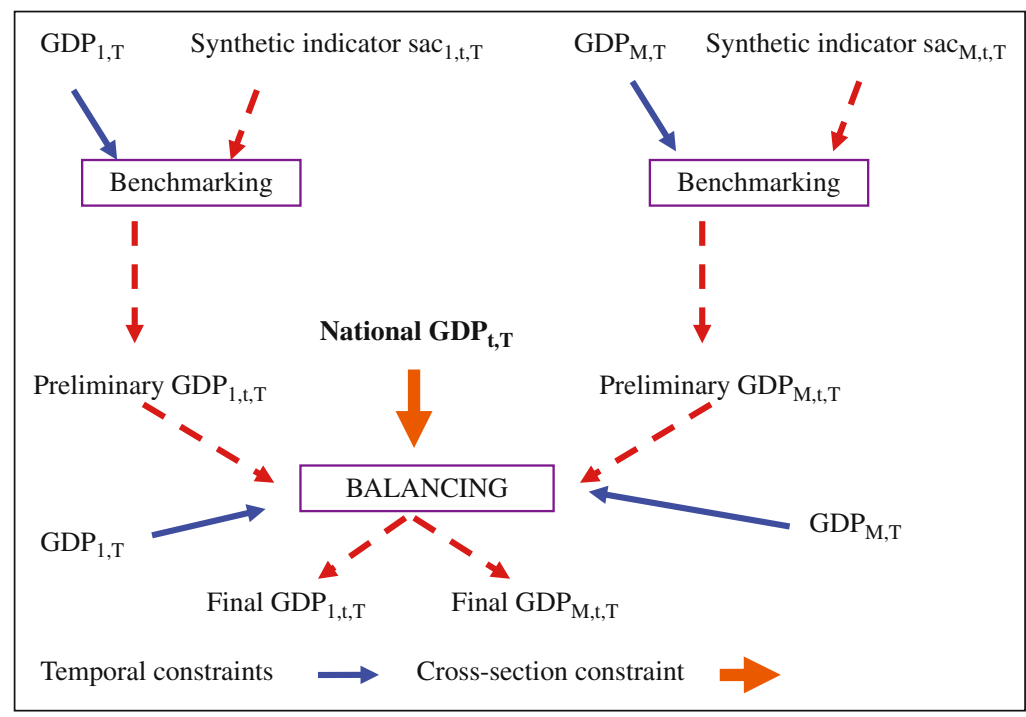

Fig. 1. Schedule of Steps 2 (Benchmarking) and 3 (Balancing). Note: national variables in bold. Quarterly index $t$ goes from 1 to 4 ; annual index $T$ goes from 1 to $N$ and regional index $j$ goes from 1 to $M$ 
rechaining steps required to circumvent the nonadditive features of the chain-linked volume indexes.

\subsection{Comparison with Other Approaches}

Table 3 compares our methodology with related approaches along six dimensions: highfrequency model, role of constraints (temporal and transversal), explicit consideration of chain linking, mixing data frequencies (e.g., annual and quarterly data) and computational approach.

Di Fonzo (1990) presents a methodology closely related to ours. We have expanded his approach to cope with the issue of chain linking and focus the results upon flash estimation and benchmarking. Di Fonzo and Marini (2005) may be considered a variant of Di Fonzo (1990) in which balancing plays also a critical role.

In addition, Proietti (2011) is also a close reference. He generalizes the Di Fonzo (1990) model to take into account integrated random-walk innovations and deals with the issue of nonadditivity posed by the chain-linking volume indexes implicitly, arranging the measurement equations to consider a statistical discrepancy. His computational approach relies on Kalman filtering of the state-space representation of the model. By contrast, our approach is matrix-oriented, following Di Fonzo (1990).

Spatial correlation plays an important role due to the fact that short-term regional indicators are closely related and the estimation of regional GDPs at the quarterly frequency depends also on the national quarterly GDP (Step 3: balancing).

However, our procedure is oriented towards the temporal disaggregation of regional aggregates, at the same time preserving the cross-section consistency with the national quarterly GDP rather than the spatial disaggregation of national totals taking the information contained in the regional indicators as the basis for interpolation. The last approach is used by the so-called spatial Chow-Lin procedure that adapts the Chow-Lin method to the spatial nature of the data and may be used to distribute a grand total into its spatial components at a given point in time (see Vidoli and Mazziotta 2012 and Polasek and Séllner 2010 among others). This procedure is very flexible and can be used to disaggregate national, regional or provincial totals into their spatial components (regions, provinces or areas), but does not consider explicitly the temporal constraints that are the hallmark of the NA, both regional and quarterly, and of our procedure.

Finally, we want to emphasize that our approach is focused on the estimation of (unobservable) quarterly regional GDPs rather than on the forecasting of the (observable) annual regional GDPs. To ensure the comparability and homogeneity of those estimates, our procedure hinges upon the temporal and cross-section consistency in the same way as implemented in the NA. The reliance on mimicking the NA limits the selection of indicators as well as the modeling approach. Lehmann and Wohlrabe (2012) present a detailed forecasting exercise at the regional level, using a variety of models and a large set of indicators with different spatial coverage.

\section{Case Study: A System of Flash Regional Quarterly GDP Estimates for Spain}

In this section we present the main results of a system of regional quarterly GDP flash estimates for the Spanish economy, following the modeling approach previously outlined. 


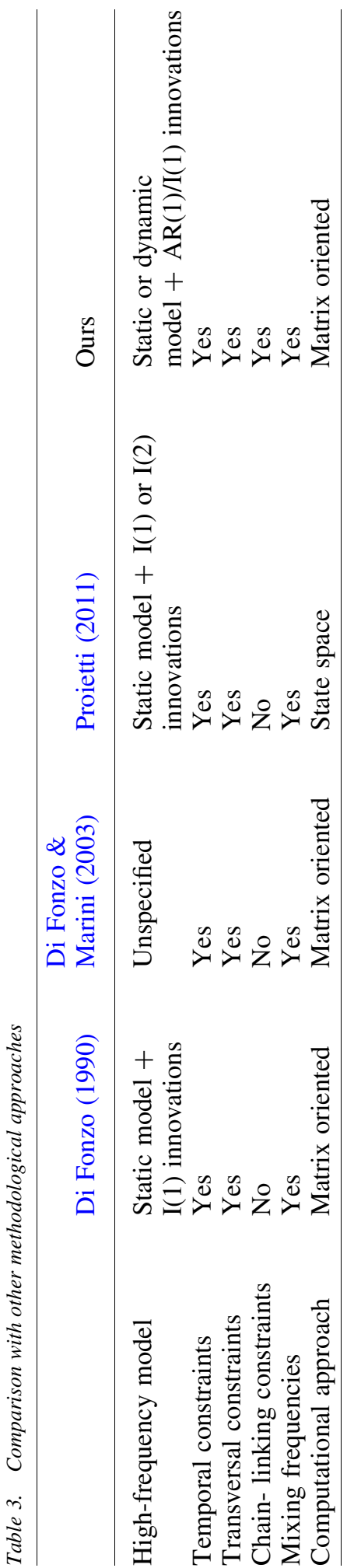




\subsection{Selection of Monthly Regional Indicators}

This subsection details the indicators that have been selected for model estimation. The selection process was carried out under the premise that indicators should be available in a timely fashion and should provide a synthetic measure of each of the regional economies.

The criterion for choosing these variables is the consideration of the regional counterpart of all the indicators used in the compilation of the QNA (see Álvarez 1989, Martínez and Melis 1989, INE 1993 and Álvarez 2005). To fulfil this goal, we have prepared a set of monthly regional indicators that provides a fairly comprehensive basis for analyzing and monitoring GDP at the regional level. This set offers a high-frequency approximation to the behavior of the main macroeconomic aggregates: gross added value (industry, construction, and services), consumption, external trade and employment. The selected indicators, with a brief description of them, are:

- IPI: Index of Industrial Production.

$\circ$ Units: Index number.

- Source: National Statistical Institute (Instituto Nacional de Estadística, INE).

- Starting date: 1995.01.

- Back-calculation: combining data from 1990 base (1995.01-2002.01) and 2005 base (2002.01-2011.12), using the oldest period-on-period rates of growth to retropolate the newest base.

- LIC: Municipal construction licenses. Total area to build.

$\circ$ Units: square meters.

- Source: Ministry of Public Works (Ministerio de Fomento).

- Starting date: 1995.01.

- Back-calculation: Data for Basque Country (País Vasco) during the period 1995.01-1997.12 have been back calculated using the average of the remaining regions as indicator. Some specific missing data (Basque Country -2008.08- and Navarra -2009.12-) have been interpolated using the program TRAMO.

- PER: Overnight stays in hotel establishments.

○ Units: Number of overnight stays.

- Source: National Statistical Institute (Instituto Nacional de Estadística, INE).

- Starting date: 1995.01.

- Back-calculation: The series have been homogenized since 1998.12 by means of univariate intervention analysis in order to correct the methodological change introduced in 1999.01.

- IAS: Services sector activity indicator.

$\circ$ Units: Index number. Valuation at current prices.

- Source: National Statistical Institute (Instituto Nacional de Estadística, INE).

- Starting date: 2005.01.

- Deflated using the Consumer Price Index (CPI) for services (house rentals excluded).

- Missing data since 1995.01 have been estimated using the static factor derived from the indicators that start in 1995.01 as regressor. 
- ICM: Retail sales index.

○ Units: Index number. Valuation at current prices, gas stations excluded.

- Source: National Statistical Institute (Instituto Nacional de Estadística, INE).

- Starting date: 2001.01.

- Deflated using the CPI for services (house rentals excluded).

- Missing data since 1995.01 have been estimated using the static factor derived from the indicators that start in 1995.01 as regressor.

- MAT: Car registrations.

○ Units: Registrations.

- Source: Traffic department (Dirección General de Tráfico, Ministerio del Interior).

- Starting date: 1995.01.

- EXP: Exports of goods.

$\circ$ Units: Euros, valuation at current prices.

- Source: External trade statistics, Ministry of Economy and Competitiveness.

- Starting date: 1995.01.

- Deflated using the national exports unit value index.

- IMP: Imports of goods.

- Units: Euros, valuation at current prices.

- Source: External trade statistics, Ministry of Economy and Competitiveness.

- Starting date: 1995.01.

- Deflated using the national imports unit value index.

- AFI: Social security system: registered workers.

o Units: persons.

- Source: Labor department (Ministerio de Empleo y Seguridad Social).

- Starting date: 1995.01.

The short-term indicators, in order to be consistent with the QNA data (as mentioned in Section 2), have been seasonally and calendar adjusted.

\subsection{Regional Synthetic Indexes}

To combine the information contained in the individual monthly indicators in an efficient and operative way, we have calculated a synthetic indicator for each region. In order to convey an idea of the correlation between the individual indicators and the estimated synthetic indicator (common factor), Table 4 shows the loading vectors, estimated by means of principal components factor analysis.

We have to note how loadings vary depending on the predominant activities in which each region specializes. Since two of the indicators (IAS and ICM) have been completed using the common factor estimated from the remaining indicators, their correlations with the common factor estimated with the balanced panel are overestimated to a certain extent. This fact complicates the exact quantification of their role. However, their economic relevance (IAS for the whole services sector and ICM for private consumption) recommends their inclusion in the estimation of the regional GDP trackers.

The corresponding monthly regional synthetic indicators are temporally aggregated to the quarterly frequency. 


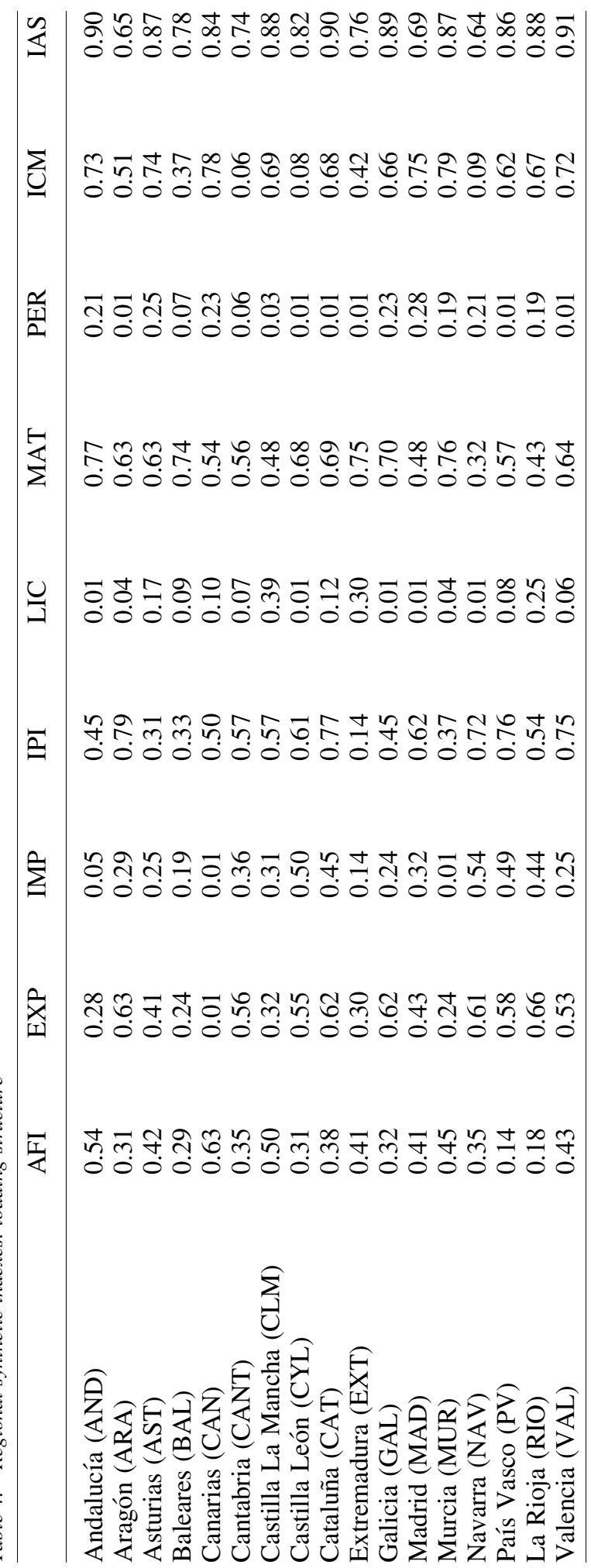




\subsection{National Accounts Data: Regional Accounts and Quarterly National Accounts}

Apart from the monthly regional indicators mentioned above, regional annual GDPs in chained-volume indices are provided by the RA according to ESA-95 conventions and they are available for the time span 1995-2011. The cross-section dimension includes 17 regions (Comunidades Autónomas) plus two autonomous cities that will be jointly considered, giving $\mathrm{M}=18$, a NUTS-2 regional breakdown according to Eurostat's classification.

Finally, the quarterly transversal constraint is the Spanish quarterly volume GDP provided by the QNA. This variable is compiled seasonally and calendar adjusted.

\subsection{Empirical Results}

Using the abovementioned data for the period 1995.01 - 2012.12 we can compare now the final results obtained using the different benchmarking techniques mentioned in section two (Fernandez, Chow-Lin, Santos Silva-Cardoso (SSC for brevity), Proportional Denton and Proietti) in order to select the most appropriate in terms of correlation and volatility.

Table 5 shows the summary results obtained with the different methods. Starting with the composite indicators derived by factor analysis for each region in the first stage, we apply different benchmarking methods and compare the different results obtained after final balancing. In order to summarize the results, we present the average correlation of the quarterly growth rate of GDP finally estimated by region with the initial composite indicator and the average standard deviation of the quarterly growth rate of GDP finally estimated by region.

This table shows that there seems to be a trade-off relationship between correlation and volatility (except in proportional Denton, which shows high volatility and low correlation). The Fernández and Chow-Lin methods are closest to the evolution of the indicator, without assuming a more complex structure in the errors, as is the case with SSC and Proietti.

Based on these results, we have decided to choose either the Fernández or the Chow-Lin method, because we think it is more important to be as faithful as possible to the information contained in the indicators, despite having higher volatility. Additionally, this is the method currently suggested for the compilation of the Spanish QNA (see Quilis 2005).

Regarding the distinction between the Fernández or Chow-Lin method, the results of the exercise show an innovational parameter with Chow-Lin close to 1 (approximately $0.98-0.99$ in most cases), so under this situation both methods are practically equivalent.

With the aim of analyzing both the duration and the date of entry and exit of the recession in each region, Table 6 presents the evolution of the estimated year-on-year rates

Table 5. Comparison of methods (quarterly rates of growth)

\begin{tabular}{llllll}
\hline & Fernandez & Chow-Lin & SSC & Denton Prop. & Proietti \\
\hline Average Standard Deviation & 0.821 & 0.858 & 0.731 & 0.843 & 0.744 \\
Average Correlation & 0.767 & 0.776 & 0.683 & 0.670 & 0.736 \\
\hline
\end{tabular}




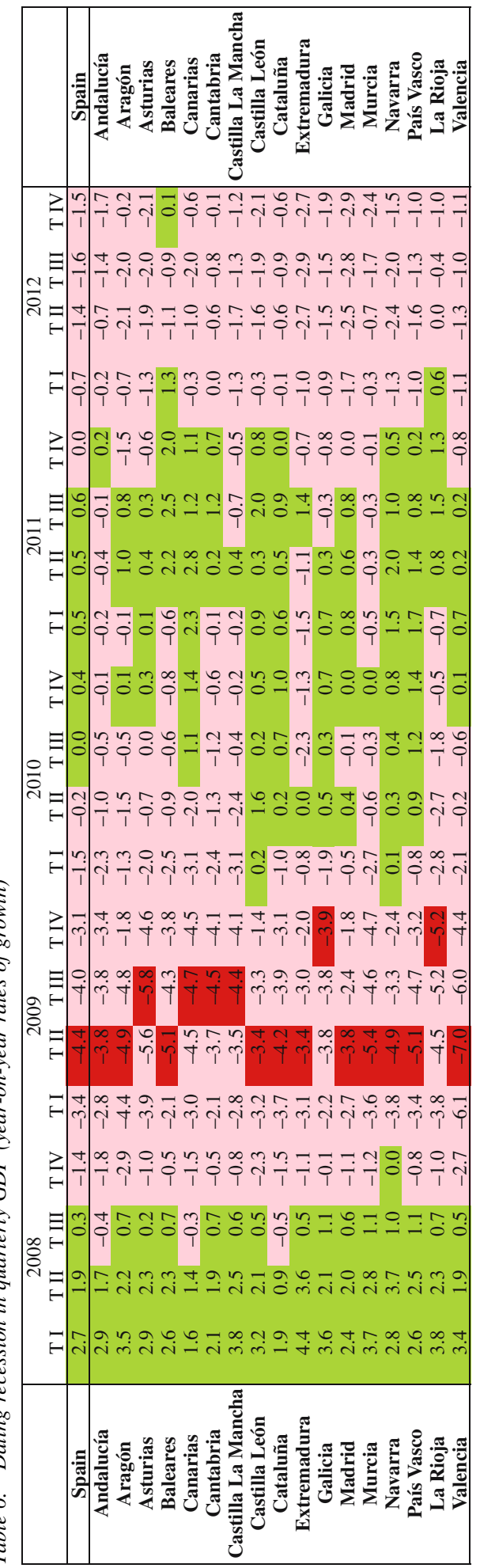


of growth in the quarterly frequency; for the exercise performed with the Chow-Lin method, for example.

The table shows how the crisis has affected regions unevenly. For example, we can place the bulk of the recession between the fourth quarter of 2008 and the first quarter of 2010. Most of the regions fell into recession at the same time but not all of them left it simultaneously; this is the case of regions such as Andalucía, where the contractionary period is particularly long. We can see that many regions fall back into recession after the first quarter of 2012.

In relation to the variance of these results, Figure 2 shows the different box plots of the year-on-year rates of growth in the quarterly frequency for the different regions:

We observe a greater presence of outliers in periods of recession than in periods of expansion. This is partly due to the longer duration of the latter, rendering the median less representative for recessionary quarters. At the same time, the highest rate of variability is not linked to the larger size (GDP weight) of the region (see Appendix 1).

The temporal dimension of the data allows us to appreciate a reduction in volatility after 2003, although this is a property inherited from the annual data published by the RA (see Figure 3):

Finally, in order to clarify the importance of the balancing procedure on the final estimate, an exercise on two regions has been carried out: one with a large size (Cataluña) and other with a small size (La Rioja). This exercise is trying to reveal whether a small region can seriously change its initial estimate of quarterly GDP with the final balancing.

Initial or preliminary estimates do not take into account the information contained in the national quarterly GDP. Those initial estimates are modified to be consistent each quarter with the quarterly national GDP, reflecting the fact that the national data is the transversal aggregation of the regions.

The difference between the initial and the final estimates reflects the balancing procedure that ensures the transversal constraint and preserves, for each region, the temporal consistency with the Regional Accounts.

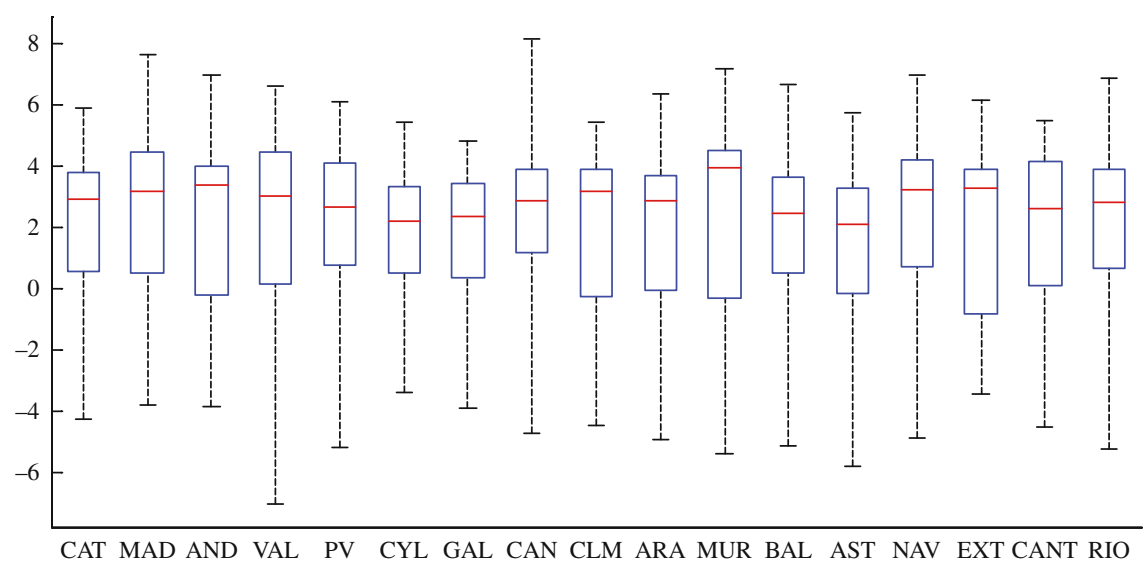

Fig. 2. Box plot: annual growth rates by region in quarterly frequency, sorted according to weight on Spanish GDP. Note: Central line stands for median values, the box represents $50 \%$ of the central part of the data and the whiskers are the minimum and maximum of the data 
Cuevas et al.: Benchmarking, Chain-Linking and Regional Analysis

643

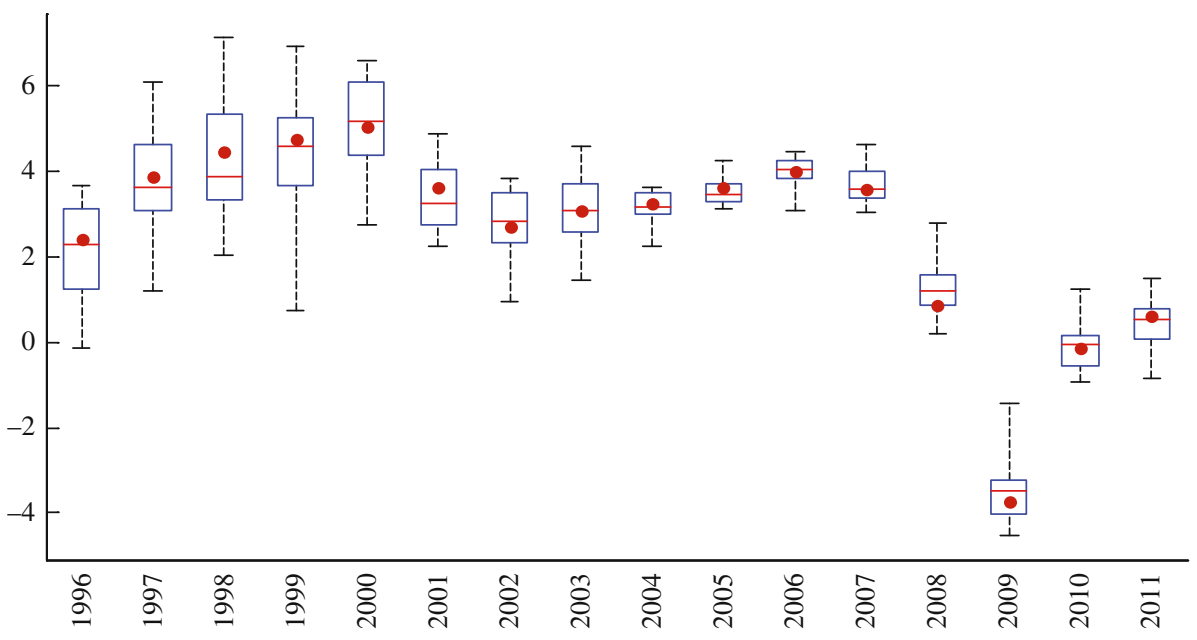

Fig. 3. Box plot: year-on-year rates of growth (annual data). Note: Dot is the aggregate data for Spain

Figure 4 shows, firstly, the initial quarterly regional GDP estimation (distribution of annual regional GDP according to the indicator) against the evolution of the indicator and, secondly, the initial quarterly estimation against the final quarterly GDP.

It is easy to see how the first step of estimating quarterly GDP depending on the evolution of the indicator is even more crucial to the subsequent balancing procedure. Furthermore, the small region does not have its initial estimate changed substantially compared with that of the large region. This fact shows the robustness of the balancing

CATALUÑa

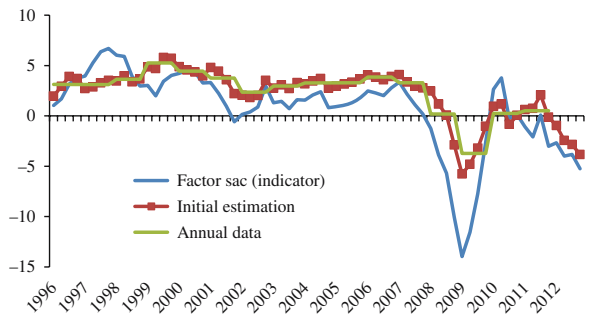

CATALUÑa

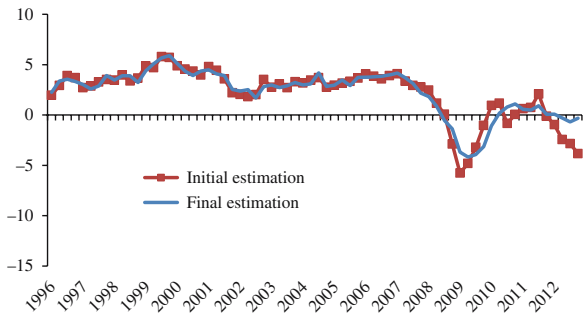

RIOJA

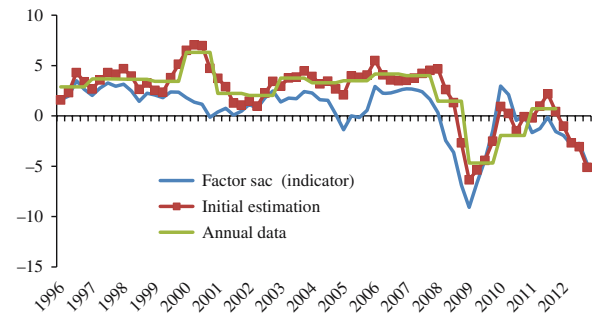

RIOJA

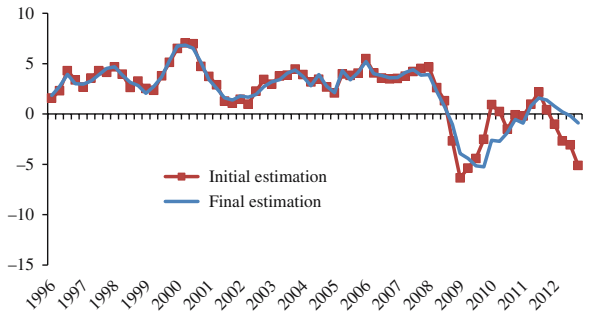

Fig. 4. Initial quarterly estimation vs. final balanced estimation. Small vs. large regions, year-on-year rates of growth 
procedure, revealing that the variability in the final estimate is driven by the variability of the selected indicator.

\section{Conclusions}

In this article we have presented a feasible way to add a regional dimension to the shortterm macroeconomic analysis, satisfying the temporal and cross-section constraints imposed by the NA. Our procedure generates results that are comparable across regions, are based on meaningful short-term information, and may be updated at the same time as the GDP flash national estimates, providing a solid basis for specific regional estimates.

In summary, the major outcomes of the model are:

- It solves the lack of quarterly GDP at the regional level, providing estimates consistent with the official available data published by the NA (RA and QNA). These estimates are a stand-alone product that may be used as input in regional econometric models.

- It provides a regional breakdown of the early estimates of the quarterly national volume GDP that may be released simultaneously, providing flash estimates at the regional level.

There are several promising lines of research that may broaden the scope of the article. The use of dynamic-factor models to estimate the regional high-frequency synthetic indexes may provide a more complete description of the economic conditions at the regional level.

The modeling approach can be extended easily to accommodate several types of extrapolations. For example, the transversal benchmark of the model (the national quarterly GDP) may be an official release made by the NSI or a forecast made by an analyst (e.g., the research department of an investment bank). In the latter case, we can combine these forecasts with the projected path for the underlying short-term quarterly regional indicators to generate the corresponding regional quarterly GDPs. The resulting conditional extrapolations can be used to assess the expected cyclical position of each region with respect to the nation.

Finally, the estimated regional quarterly GDPs can be used to analyze issues related to the synchronicity of the regional business cycles as well as their pattern of co-movements. 
Appendix 1: Main Features of the Spanish Regions (2011)

\begin{tabular}{lrrrr}
\hline & $\begin{array}{c}\text { Population } \\
\text { (thousand) }\end{array}$ & $\begin{array}{c}\text { Population } \\
\text { weight }\end{array}$ & $\begin{array}{c}\text { GDP } \\
\text { weight }\end{array}$ & $\begin{array}{c}\text { Employment } \\
\text { weight }\end{array}$ \\
\hline Andalucía & $8,270.5$ & $17.9 \%$ & $13.5 \%$ & $14.7 \%$ \\
Aragón & $1,315.5$ & $2.9 \%$ & $3.2 \%$ & $3.1 \%$ \\
Asturias & $1,054.5$ & $2.3 \%$ & $2.1 \%$ & $2.1 \%$ \\
Baleares & $1,092.5$ & $2.4 \%$ & $2.5 \%$ & $2.6 \%$ \\
Canarias & $2,107.0$ & $4.6 \%$ & $3.9 \%$ & $4.1 \%$ \\
Cantabria & 578.3 & $1.3 \%$ & $1.2 \%$ & $1.2 \%$ \\
Castilla La Mancha & $2,045.4$ & $4.4 \%$ & $3.5 \%$ & $3.9 \%$ \\
Castilla León & $2,483.8$ & $5.4 \%$ & $5.3 \%$ & $5.3 \%$ \\
Cataluña & $7,303.1$ & $15.8 \%$ & $18.6 \%$ & $17.8 \%$ \\
Extremadura & $1,083.1$ & $2.3 \%$ & $1.6 \%$ & $1.9 \%$ \\
Galicia & $2,732.0$ & $5.9 \%$ & $5.3 \%$ & $5.7 \%$ \\
Madrid & $6,371.6$ & $13.8 \%$ & $18.0 \%$ & $16.8 \%$ \\
Murcia & $1,471.4$ & $3.2 \%$ & $2.6 \%$ & $3.0 \%$ \\
Navarra & 622.8 & $1.4 \%$ & $1.7 \%$ & $1.6 \%$ \\
País Vasco & $2,127.9$ & $4.6 \%$ & $6.2 \%$ & $5.3 \%$ \\
La Rioja & 312.7 & $0.7 \%$ & $0.8 \%$ & $0.7 \%$ \\
Valencia & $5,001.2$ & $10.8 \%$ & $9.5 \%$ & $9.8 \%$ \\
Ceuta y Melilla & 151.7 & $0.3 \%$ & $0.3 \%$ & $0.3 \%$ \\
\hline Spain & $46,125.0$ & $100.0 \%$ & $100.0 \%$ & $100.0 \%$ \\
\hline
\end{tabular}

\section{References}

Abad, A. and E.M. Quilis. 2005. "Software to Perform Temporal Disaggregation of Economic Time Series.” Eurostat, Working Papers and Series. Available at: http://ec. europa.eu/eurostat/documents/4187653/5774917/LN-SR012007-EN.PDF/c83eb69ee3a9-4fdd-923d-76c09fea6f7b (accessed October 2015).

Abad, A., A. Cuevas, and E.M. Quilis. 2007. "Chain-Linked Volume Indexes: a Practical Guide." Universidad Carlos III de Madrid, Instituto Flores de Lemus, Boletín de Inflación y Análisis Macroeconómico 157: 72-85. Available at http://e-archivo.uc3m. es/handle/10016/20332\#preview (accessed October 2015).

Álvarez, F. 1989. "Base Estadística en España de la Contabilidad Nacional Trimestral." Revista Española de Economía 6: 59-84.

Álvarez, R. 2005. "Notas Sobre Fuentes Estadísticas.” In Servicio de Estudios del Banco de España, El análisis de la economía española, Alianza Editorial, Madrid, Spain.

Bloem, A.M., R.J. Dippelsman, and N.O. Mæhle. 2001. Quarterly National Accounts Manual. Concepts, Data Sources, and Compilation. International Monetary Fund. Available at: https://www.imf.org/external/pubs/ft/qna/2000/Textbook/ch1.pdf (accessed October 2015).

Bournay, J. and G. Laroque. 1979. "Réflexions sur la Méthode D’elaboration des Comptes Trimestriels.” Annales de l'INSEE 36: 3-30. Available at: http://www.jstor.org/stable/ 20075332. 
Caporello, G. and A. Maravall. 2004. "Program TSW. Revised Manual." Bank of Spain, Occasional Paper no. 0408. http://www.bde.es/f/webbde/SES/Secciones/ Publicaciones/PublicacionesSeriadas/DocumentosOcasionales/04/Fic/do0408e.pdf (accessed October 2015).

Chow, G. and A.L. Lin. 1971. "Best Linear Unbiased Distribution and Extrapolation of Economic Time Series by Related Series." Review of Economic and Statistics 53: 372-375. Available at: http://www.jstor.org/stable/1928739.

Denton, F.T. 1971. “Adjustment of Monthly or Quarterly Series to Annual Totals: an Approach Based on Quadratic Minimization." Journal of the American Statistical Society 66: 99-102. Doi: http://dx.doi.org/10.1080/01621459.1971.10482227.

Di Fonzo, T. 1987. La Stima Indiretta di Serie Economiche Trimestrali. Cleup Editore, Padova, Italy.

Di Fonzo, T. 1990. "The Estimation of $M$ Disaggregate Time Series when Contemporaneous and Temporal Aggregates are Known." Review of Economics and Statistics 72: 178-182. Doi: http://dx.doi.org/10.2307/2109758.

Di Fonzo, T. 2002. "Temporal Disaggregation of Economic Time Series: Towards a Dynamic Extension." European Commission (Eurostat) Working Papers and Studies, Theme 1, General Statistics (pp. 41). Available at: http://ec.europa.eu/eurostat/ documents/3888793/5816173/KS_AN-03-035-EN.PDF/21c4417c-dbec-45ec-b440fe8bf95661b7?version=1.0 (accessed October 2015).

Di Fonzo, T. and M. Marini. 2003. "Benchmarking Systems of Seasonally Adjusted Time Series According to Denton's Movement Preservation Principle." Dipartimento di Scienze Statistiche, Università di Padova, Working Paper no. 2003-09. Available at: http://www.oecd.org/std/21778574.pdf, (accessed October 2015).

Eurostat. 1998. Handbook of Quarterly National Accounts. Luxembourg: Statistical Office of the EC.

Fernández, R.B. 1981. "Methodological Note on the Estimation of Time Series." Review of Economic and Statistics 63: 471-478. Doi: http://dx.doi.org/10.2307/1924371.

Gómez, V. and A. Maravall. 1996. "Programs TRAMO and SEATS." Bank of Spain, Working Paper no. 9628. Available at: http://www.bde.es/f/webbde/SES/Secciones/ Publicaciones/PublicacionesSeriadas/DocumentosTrabajo/96/Fich/dt9628e.pdf (accessed October 2015).

Gómez, V. and A. Maravall (1998a) "Guide for using the programs TRAMO and SEATS", Bank of Spain, Working Paper no. 9805. Available at: http://www.bde.es/f/webbde/ SES/Secciones/Publicaciones/PublicacionesSeriadas/DocumentosTrabajo/98/Fic/ dt9805e.pdf (accessed October 2015).

Gómez, V. and A. Maravall (1998b) “Automatic modeling methods for univariate series", Bank of Spain, Working Paper no. 9808. Available at: http://www.bde.es/f/webbde/ SES/Secciones/Publicaciones/PublicacionesSeriadas/DocumentosTrabajo/98/Fic/ dt9808e.pdf (accessed October 2015).

Gregoir, S. 1994. "Propositions Pour une Désagrégation Temporelle Basée sur des Modèles Dynamiques Simples." In Workshop on Quarterly National Accounts, ed. Eurostat. Luxembourg: Statistical Office of the EC. Available at: http://ec.europa. eu/eurostat/documents/3888793/5815741/KS-AN-03-014-EN.PDF/284f1001-fd364999-b007-a22033e8aaf9 (accessed October 2015). 
INE. 1993. Contabilidad Nacional Trimestral de España (CNTR). Metodología y serie trimestral 1970-1992. Instituto Nacional de Estadística.

Litterman, R.B. 1983. "A random walk, Markov model for the distribution of time series." Journal of Business and Economic Statistics 1: 169-173. Available at: http://www. jstor.org/stable/1391858.

Lehmann, R. and K. Wohlrabe. 2012. "Forecasting GDP at the Regional Level with Many Predictors.” CESIFO, Working Paper no. 3956. Available at: http://www-sre.wu.ac.at/ ersa/ersaconfs/ersa13/ERSA2013_paper_00015.pdf (accessed October 2015).

Martínez, A. and F. Melis. 1989. "La Demanda y la Oferta de Estadísticas Coyunturales." Revista Española de Economía 6: 7-58.

Polasek, W. and R. Séllner. 2010. "Spatial Chow-Lin Methods for Data Completion in Econometric Flow Models." Institut für Höhere Studien (HIS), Economic Series no. 255. Available at: https://www.ihs.ac.at/publications/eco/es-255.pdf (accessed October 2015).

Proietti, T. 2006. "Temporal Disaggregation by State Space Methods: Dynamic Regression Methods Revisited.” Econometrics Journal 9: 357-372. Doi: http://dx.doi. org/10.1111/j.1368-423X.2006.00189.

Proietti, T. 2011. "Multivariate Temporal Disaggregation with Cross-Sectional Constraints." Journal of Applied Statistics 38: 1455-1466. Doi: http://dx.doi.org/ 10.1080/02664763.2010.505952.

Quilis, E.M. 2005. "Benchmarking Techniques in the Spanish Quarterly National Accounts." European Commission, Working papers and studies (Eurostat-OECD Workshop on Frontiers in Benchmarking Techniques and Their Application to Official Statistics, Luxembourg, April 7-8, 2005). Available at: http://ec.europa.eu/eurostat/ documents/4187653/5774917/LN-SR012007-EN.PDF/c83eb69e-e3a9-4fdd-923d76c09fea6f7b (accessed October 2015).

Salazar, E., R. Smith, S. Wright, and M. Weale. 1994. "Indicators of Monthly National Accounts." In Workshop on Quarterly National Accounts, ed. Eurostat. Luxembourg: Statistical Office of the EC. Available at: http://ec.europa.eu/eurostat/documents/ 3888793/5815741/KS-AN-03-014-EN.PDF/284f1001-fd36-4999-b007-a22033e8aaf9 (accessed October 2015).

Santos-Silva, J.M.C. and F. Cardoso. 2001. "The Chow-Lin Method Using Dynamic Models." Economic Modelling 18: 269-280. Doi: http://dx.doi.org/10.1016/ S0264-9993(00)00039-0.

Vidoli, F. and C. Mazziotta. 2012. "Spatial Composite and Disaggregate Indicators: Chow-Lin Methods and Applications." Real Estate 2: 9-19. Available at: http://fvidoli. weebly.com/uploads/2/3/0/8/23088460/eng_spatialcompositeanddisaggregate.pdf (accessed October 2015).

Received February 2013

Revised January 2015

Accepted January 2015 